\title{
Ammonia induced microglia activation was associated with limited effects on connexin 43 and aquaporin 4 expression in an astrocyte-microglia co-culture model
}

Fatme Seval Ismail ${ }^{1 *+} \mathbb{B}$, Timo Jendrik Faustmann ${ }^{2 \dagger}$, Franco Corvace $^{3}$, Anamariya Tsvetanova ${ }^{3}$, Zahra Moinfar ${ }^{3,4}$ and Pedro M. Faustmann 3,4

\begin{abstract}
Background: Hepatic encephalopathy (HE) is a neurological complication resulting from acute or chronic liver disease. Hyperammonemia leading to astrocyte swelling and cerebral edema in combination with neuroinflammation including microglia activation, mainly contribute to the pathogenesis of HE. However, little is known about microglia and their inflammatory response, as well as their influence on astrocytic channels and astrocyte swelling under hyperammonemia.
\end{abstract}

Objective: To investigate the effects of ammonia on the microglial activation and morphology in different set-ups of an in vitro astrocyte-microglia co-culture model. Further, potential effects on glial viability, connexin 43 (Cx43) and aquaporin 4 (AQP4) expression were tested.

Methods: Primary rat glial co-cultures of astrocytes containing 5\% (M5, representing "physiological" conditions) or 30\% (M30, representing "pathological" conditions) of microglia were incubated with 3 mM, 5 mM, 10 mM and 20 mM ammonium chloride $(\mathrm{NH} 4 \mathrm{Cl})$ for $6 \mathrm{~h}$ and $24 \mathrm{~h}$ in order to mimic the conditions of HE. An MTT assay was performed to measure the viability, proliferation and cytotoxicity of cells. The microglial phenotypes were analyzed by immunocytochemistry. The expression of $\mathrm{Cx} 43$ and AQP4 were quantified by immunoblot analysis.

Results: A significant reduction of glial viability was observed in M30 co-cultures after incubation with $20 \mathrm{mM} \mathrm{NH4Cl}$ for $6 \mathrm{~h}$, whereas in M5 co-cultures the viability remained unchanged. Microglial activation was detected by immunocytochemistry after incubation with $3 \mathrm{mM}, 5 \mathrm{mM}$ and $10 \mathrm{mM} \mathrm{NH} 4 \mathrm{Cl}$ for $6 \mathrm{~h}$ and $24 \mathrm{~h}$ in M5 as well as in M30 cocultures. The Cx43 expression was slightly increased in M30 co-cultures after $6 \mathrm{~h}$ incubation with $5 \mathrm{mM} \mathrm{NH4Cl}$. Also, the AQP4 expression was slightly increased only in M5 co-cultures treated with $10 \mathrm{mM} \mathrm{NH4Cl}$ for $6 \mathrm{~h}$. Under the other conditions, $\mathrm{C} \times 43$ and AQP4 expression was not affected by NH4Cl.

Conclusions: The novel aspect of our study was the significant microglial activation and decrease of viability after $\mathrm{NH} 4 \mathrm{Cl}$ incubation in different set-ups of an in vitro astrocyte-microglia co-culture model, contributing to better

\footnotetext{
*Correspondence: ismaf88@gmail.com

${ }^{\dagger}$ Fatme Seval Ismail and Timo Jendrik Faustmann have equally contributed as first authors

1 Department of Neurology, University Hospital Knappschaftskrankenhaus

Bochum, Ruhr University Bochum, Bochum, Germany

Full list of author information is available at the end of the article
}

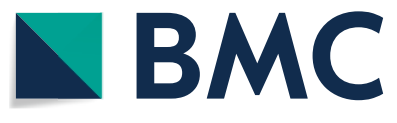

(c) The Author(s) 2021. This article is licensed under a Creative Commons Attribution 4.0 International License, which permits use, sharing, adaptation, distribution and reproduction in any medium or format, as long as you give appropriate credit to the original author(s) and the source, provide a link to the Creative Commons licence, and indicate if changes were made. The images or other third party material in this article are included in the article's Creative Commons licence, unless indicated otherwise in a credit line to the material. If material is not included in the article's Creative Commons licence and your intended use is not permitted by statutory regulation or exceeds the permitted use, you will need to obtain permission directly from the copyright holder. To view a copy of this licence, visit http://creativeco mmons.org/licenses/by/4.0/. The Creative Commons Public Domain Dedication waiver (http://creativecommons.org/publicdomain/ zero/1.0/) applies to the data made available in this article, unless otherwise stated in a credit line to the data. 
understanding of pathophysiological mechanisms of HE. Hyperammonemia led to limited effects on Cx43 and AQP4 expression, the relevance of these minimal changes should be viewed with caution.

Keywords: Ammonia, Astrocyte-microglia co-culture model, Microglial activation, Connexin 43, Aquaporin 4

\section{Background}

Hepatic encephalopathy (HE) is a neurological complication resulting from acute or chronic liver disease. High ammonia level resulting from impaired liver function can cross the blood-brain-barrier and lead to morphological changes of astrocytes $[1,2]$. Further, astrocytes are the main cells in the central nervous system (CNS) which can metabolize ammonia into glutamine using glutamine synthetase [3, 4]. Elevated ammonia and glutamine level in astrocytes results in increased water accumulation, cytotoxic astrocyte swelling and increased osmotic pressure contributing to cerebral edema, and correlates with the state of HE [5-8]. Studies have also shown that the transmembrane water channel protein Aquaporin 4 (AQP4), which is localized on astrocyte end-feet and regulates maintaining brain water homeostasis, is up-regulated during acute liver failure and HE [9-14].

Microglia, the main immune cells of the CNS, are found in a resting ramified form in the healthy brain and range from 5 to $20 \%$ of the glial cell population [15]. Under pathological conditions, microglial activation includes proliferation of microglia, change of the morphological phenotype from the resting ramified type (RRT) to the activated, rounded phagocytic type (RPT), expression of immune molecules and release of inflammatory mediators [16]. Intermediate type of microglia (INT) represents the phenotypic transition from resting ramified to the activated type and are characterized by short cell processes. Studies have demonstrated that hyperammonemia in HE leads to microglia activation in terms of stimulation of microglial cell migration, morphological changes, oxidative stress and up-regulation of the microglial activation marker ionized calcium-binding adaptor molecule-1 (Iba-1) [17]. Media from ammoniatreated microglia cell culture added to cultured astrocytes contributes to astrocyte swelling suggesting a link between astrocytes and microglia under hyperammonemia conditions [18].

In summary, hyperammonemia leading to astrocyte swelling and cerebral edema in combination with neuroinflammation including microglia activation, mainly contribute to the pathogenesis of $\mathrm{HE}$.

Connexin $43(\mathrm{C} \times 43)$ is the predominant protein in astrocytes that contributes to formation of gap junctions (GJs) and functional astrocytic network allowing the exchange of small molecules, ions and second messengers, and ensuring the homeostasis [19]. Connexin 43 is further involved in spatial buffering of potassium, cell proliferation, regulation of transmitter uptake and dissipation, support of neurons, and volume regulation [15, 19]. There is evidence that gap-junctional coupling of astrocytes plays a role in ammonia-induced cytotoxicity [20]. No data about effects of ammonia on Cx43 expression in astrocytes are available to date. Also, little is known about microglia and their influence on astrocytic channels and astrocyte swelling under hyperammonemia. In this study, we aimed to investigate the effects of ammonia on the microglial activation and morphology in different set-ups of an in vitro astrocyte-microglia coculture model. Further, potential effects on glial viability, connexin $43(\mathrm{Cx} 43)$ and aquaporin $4(\mathrm{AQP} 4)$ expression were tested.

\section{Methods}

\section{Cell culture}

Primary astrocyte-microglia co-cultures were derived from brain of postnatal Wistar rats (postnatal day 0-2, P0-P2) according to Faustmann et al. [15]. All experiments were performed according to the German animal welfare act and the ethical standards of Ruhr University Bochum, and were approved by the local authorities in Bochum, Germany. All animals were kept under standard laboratory conditions with access to food and water.

The P0-P2 rats were decapitated without sedation, according to the German animal welfare act. After removing of cerebellum, meninges and choroid plexus, the brains were kept in ice-cold phosphatebuffered saline (PBS) (containing 1,38 M NaCl, $27 \mathrm{mM} \mathrm{KCl,} 81 \mathrm{mM}$ NaH2PO4, 14,7 mM K2H2PO4 (J.T. Baker, Deventer, the Netherlands), then treated with $0.1 \%$ trypsin (PAA laboratories, Pasching, Austria) for $30 \mathrm{~min}$ at $37^{\circ} \mathrm{C}$ and centrifuged at $500 \times g$ for $12 \mathrm{~min}$ to remove the supernatant. Following this, the pellet was resuspended in $5 \mathrm{ml}$ of DNase I solution (Serva Electrophoresis, Heidelberg, Germany) $(100 \mu \mathrm{l} / \mathrm{ml}$ with Dulbecco's minimal essential medium, DMEM, Invitrogen, Karlsruhe, Germany) for $5 \mathrm{~min}$ at room temperature, centrifuged at $200 \times \mathrm{g}$ for 5 min and after washing steps (washing medium containing 10\% FCS (Biochrom AG, Berlin, Germany), 1\% penicilin/ streptomycin solution (PAA Laboratories, Linz, Austria)) filtered through a $60-\mu \mathrm{m}$ nylon mesh. Cells were kept at a density of one brain per plastic tissue-culture flask in $7 \% \mathrm{CO} 2$ at $37{ }^{\circ} \mathrm{C}$ in astrocyte culture medium (containing 10\% fetal calf serum, $1 \%$ non-essential amino 
acids, $1 \%$ glutamine, $1 \%$ penicilin/streptomycin solution) (PAA Laboratories, Linz, Austria). After 5 days, the cultures were about $100 \%$ confluent. Adherent microglial cells and oligodendroglia on the astroglial surface were separated from the culture by shaking the flasks manually. The amount of microglial cells in the co-cultures varied between 5 and 30\% depending on the extent of shaking and was determined by counting after fixation and staining.

\section{Treatment of cultures}

The primary rat glial co-cultures of astrocytes containing 5-10\% (M5, representing "physiological" conditions) or $30-40 \%$ (M30, representing "pathological" conditions) of microglia were incubated with $3 \mathrm{mM}, 5 \mathrm{mM}, 10 \mathrm{mM}$ and $20 \mathrm{mM}$ ammonium chloride $(\mathrm{NH} 4 \mathrm{Cl}$ ) (diluted in $\mathrm{H} 2 \mathrm{O}$ ) (Sigma-Aldrich, Germany) for $6 \mathrm{~h}$ and $24 \mathrm{~h}$ in $7 \% \mathrm{CO}_{2}$ at $37{ }^{\circ} \mathrm{C}$ in order to mimic the conditions of HE. Because the survival of the glial cells after incubation with high concentration $(20 \mathrm{mM})$ of $\mathrm{NH} 4 \mathrm{Cl}$ can be affected, it was not used for experiments testing microglia morphology, Cx43 and AQP4 expression.

\section{MTT assay}

An MTT (3-(4,5-dimethylthiazol-2-yl)-2,5-diphenyltetrazolium bromide) assay (Roche applied sciences) was performed to measure the viability, proliferation and cytotoxicity of cells. The co-cultures from tissue-culture flask were placed on poly-L-lysine-coated glass cover slips at 12,000 cells per well in 94-well plates in $7 \% \mathrm{CO}_{2}$ at $37{ }^{\circ} \mathrm{C}$ until they were confluent. Cells were incubated with ammonium chloride as described above. In the next step, incubation with $10 \mu \mathrm{l}$ MTT reagent for $4 \mathrm{~h}$ in $7 \%$ $\mathrm{CO} 2$ at $37^{\circ} \mathrm{C}$ was performed. Following this, $100 \mu \mathrm{l}$ of solubilization solution were applied to the co-cultures and the samples were incubated overnight. The next day, the Bio-rad microplate reader (München, Germany) was used to measure the cell viability in the wells at a wavelength of $550 \mathrm{~nm}$.

\section{Immunocytochemistry}

The microglial phenotypes as well as $\mathrm{Cx} 43$ and AQP4 expression were analyzed by immunocytochemistry. The astrocyte-microglia co-cultures were placed on polyL-lysine-coated glass cover slips at 70,000 cells per well in 24-well plates and incubated with ammonium chloride as described above. Cover slips with the cell cultures were fixed with 70\% ethanol for $10 \mathrm{~min}$ and incubated in PBSblocking solution containing $1 \%$ bovine serum albumin (1\% BSA) (PAA Laboratories, Linz, Austria). The cover slips were treated with rabbit anti-Cx43 (1:2000) (Invitrogen, Karlsbad, Germany) and rabbit anti-AQP4 (1:200) (Invitrogen, Karlsbad, Germany) in combination with mouse anti-ED1 (1:250) (Serotec, Düsseldorf, Germany) (diluted in $1 \%$ BSA in PBS) and incubated at $4{ }^{\circ} \mathrm{C}$ for $2 \mathrm{~h}$. In the next step, the wells were incubated with secondary antibodies (1:500) (diluted in 1\% BSA, 10\% horse serum in PBS) (Invitrogen, Karlsruhe, Germany) including goat anti-mouse IgG conjugates (Alexa fluor ${ }^{\circledR} 568$ ) and goat anti-rabbit IgG conjugates (Alexa fluor ${ }^{\circledR} 488$ ) for $1 \mathrm{~h}$. Immunocytochemically labeled cells were counterstained with DAPI (4,6-diamidino-2-phenyl-indol, 1:2500) (Invitrogen, Karlsruhe, Germany) for quantification of cell numbers. The ratio of microglia to astrocytes was identified by comparison of the number of ED1-stained microglia with the total number of DAPI-labeled cells. The microglia morphology was evaluated in a minimum of three different visual fields on each cover slip at a primary magnification of $630 \times$ (total of $n=52)$. ED1 staining allowed the classification of microglia as ramified, intermediate and activated rounded phagocytic phenotype [11] (Fig. 1).

\section{Immunoblot (western blot) analysis}

The expression of $\mathrm{Cx} 43$ and AQP4 were quantified by immunoblot analysis according to the protocol. A total number of 300.000 cells were seeded in each culture dish. After reaching confluence, the cells were treated with ammonium chloride as described above. In the next step, the cells were washed with PBS and lysed with $200 \mu \mathrm{l}$ Laemmli $1 \times$ buffer and $4 \mu$ protease inhibitor cocktail. The cells were detached from the culture dishes using a silicone scraper and the lysates were kept on ice. The protein concentrations were measured by Bradford assay (Bio-rad Bradford Protein Assay, München, Germany) based on the protocol [21]. Next, loading of $10 \mu \mathrm{g}$ solution onto $10 \%$ or $15 \%$ sodium dodecyl sulfate (SDS) gel (AppliChem, Darmstadt, Germany) and electrophoresis at $100 \mathrm{~V}$ for $20 \mathrm{~min}$ and following $150 \mathrm{~V}$ was performed. After transfer of the gels to nitrocellulose membrane for Cx43 or polyvinylidene fluoride (PVDF) membrane for AQP4 and blocking with Odyssey blocking buffer (LICOR Bioscience, Germany) for $1 \mathrm{~h}$, the membranes were incubated with anti- $\beta$-actin $(1: 10,000)$ (Sigma, St.Louis, USA), anti-Cx43 (1:5000) (Invitrogen, Karlsbad, Germany) or anti-AQP4 (1:2000) (Invitrogen, Karlsbad, Germany) antibodies (diluted in 0,5\% blocking buffer) at $4{ }^{\circ} \mathrm{C}$ overnight. After washing with $0.1 \%$ Tween ${ }^{\circledR} 20$ (AppliChem, Darmstadt, Germany) in PBS (PBST) for $3 \times 15 \mathrm{~min}$, the membranes were treated with secondary anti- $\beta$-actin peroxidase goat anti-mouse $(1: 20,000)$ and peroxidase goat anti-rabbit $(1: 10,000)$ fluorescent antibodies (Sigma, St.Louis, USA) (diluted in 0,5\% blocking buffer) for $1 \mathrm{~h}$. Washing step with PBST was performed. The Odyssey Infrared Imaging System (LI-COR Bioscience, Germany) was used to visualize the bands. 

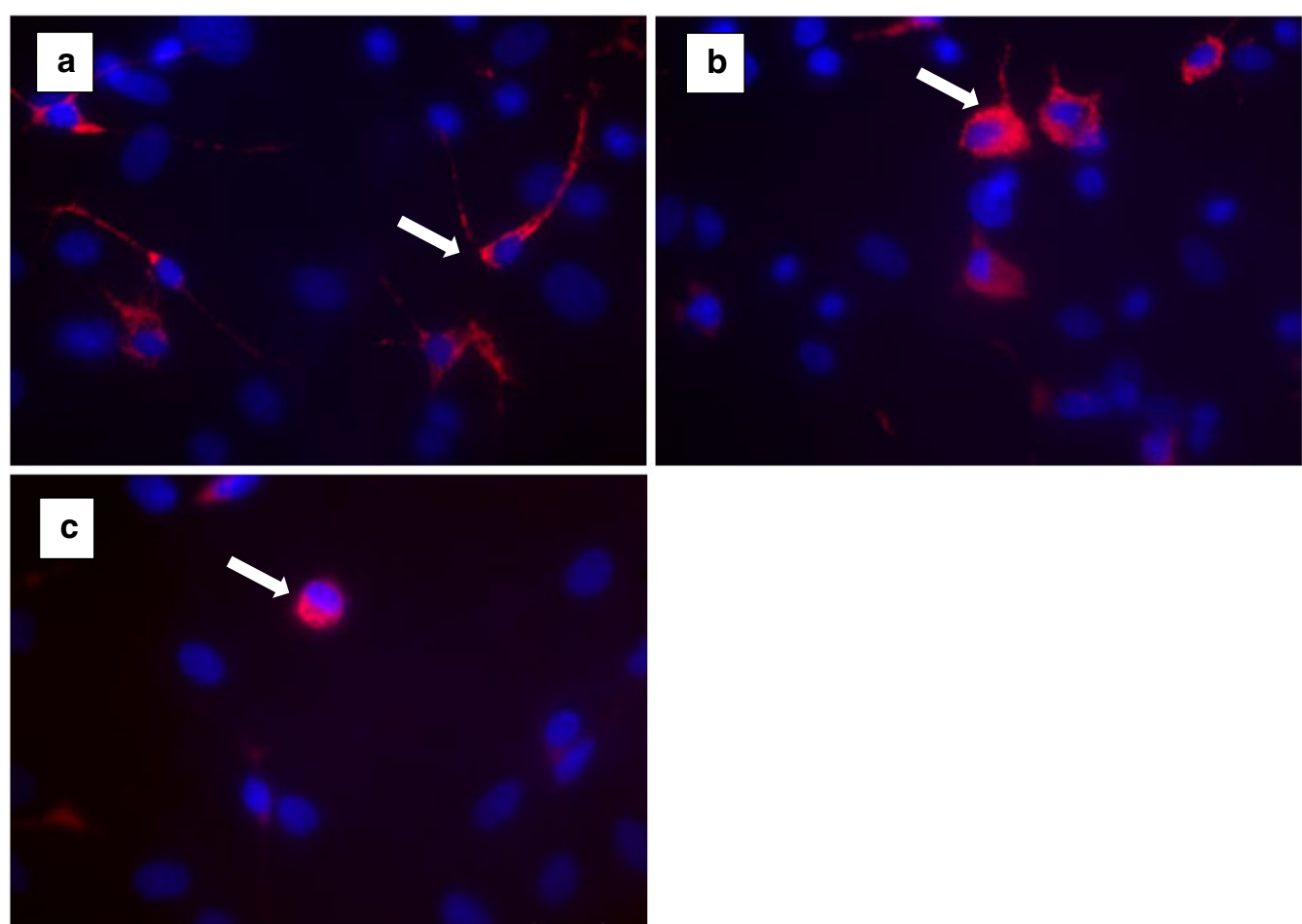

Fig. 1 Microglia morphology (white arrows) at a magnification of $630 \times$. ED1 staining allowed the classification of microglia as resting ramified (a) intermediate (b) and activated rounded phagocytic (c) phenotype under hyperammonemia

Subsequent quantification of the bands was performed using ImageStudio Lite V5.2 software from LI-COR. The percentage of $\mathrm{Cx} 43$ and AQP4 was quantified using Microsoft Excel in ratio to the beta-actin band.

\section{Data analyses and statistics}

All statistical analyses and graphs were performed with GraphPad Prism version 6.0 for Windows (GraphPad Software, San Diego, USA). Normality of data distribution was analyzed using the Kolmogorov-Smirnov tests and D'Agostino-Pearson omnibus tests. Parametric test were only applied when normality was given. Comparisons between more than two groups with normal distribution were analyzed using One-way analysis of variance (One-way ANOVA) and Kruskal-Wallis test. The significance was set at $\mathrm{p}<0.05$ and the results were reported as mean \pm standard error of the mean.

\section{Results}

\section{Glial viability after incubation with ammonia}

A significant reduction of glial viability was observed after incubation with $20 \mathrm{mM} \mathrm{NH} 4 \mathrm{Cl}$ for $6 \mathrm{~h}$ in M30 co-cultures, representing "pathological " conditions $(\mathrm{p}<0.001)$ (Fig. 2b). This effect could not be observed after incubation for $24 \mathrm{~h}$. In M5 co-cultures, representing "physiological" conditions, the glial viability was not altered by hyperammonemia (Fig. 2a).

\section{Hyperammonemia-induced microglial activation}

We detected a significant and dose-dependent increase of amount of activated microglia in M5 and M30 cocultures by immunocytochemistry after incubation with $5 \mathrm{mM}$ and $10 \mathrm{mM} \mathrm{NH} 4 \mathrm{Cl}$ for 6 and $24 \mathrm{~h}$ (Fig. 3a, c). In parallel, the amount of resting microglia decreased significantly and dose-dependent under the same conditions (Fig. 3a, c). Further the amount of intermediate type of microglia was increased significantly in M5 co-cultures after incubation with $5 \mathrm{mM}$ and $10 \mathrm{mM} \mathrm{NH} 4 \mathrm{Cl}$ for $6 \mathrm{~h}$ $(\mathrm{p}<0.05)$ and in M30 co-cultures after incubation with $3 \mathrm{mM}$ and $5 \mathrm{mM} \mathrm{NH} 4 \mathrm{Cl}$ for $6 \mathrm{~h}(\mathrm{p}<0.01)$ (Fig. 3b).

\section{Influence of ammonia on Cx43 expression}

The Cx43 expression in M5 co-cultures was not changed significantly in immunoblot analysis after incubation with different concentrations of $\mathrm{NH} 4 \mathrm{Cl}$ for 6 or $24 \mathrm{~h}$ (Fig. 4a). Under "pathological" conditions in M30 co-cultures, the Cx43 expression was significantly increased after $6 \mathrm{~h}$ incubation with $5 \mathrm{mM} \mathrm{NH} 4 \mathrm{Cl}(\mathrm{p}<0.05)$ and weakly, but not significantly increased after incubation with $10 \mathrm{mM}$ $\mathrm{NH} 4 \mathrm{Cl}$ (Figs. 4b and 6a). An additional file shows original, unprocessed versions of full-length representative 
a

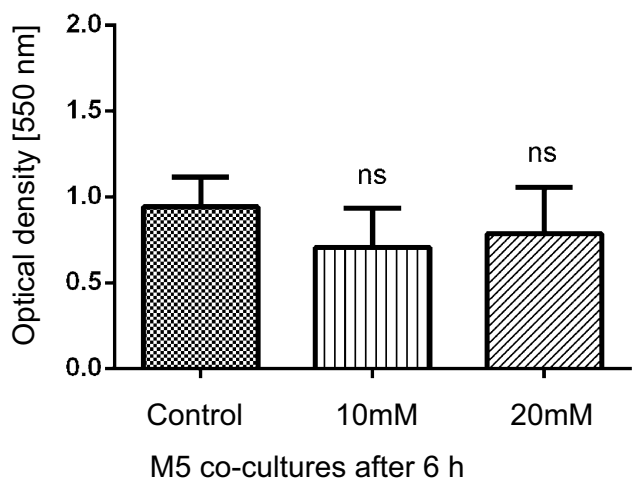

b

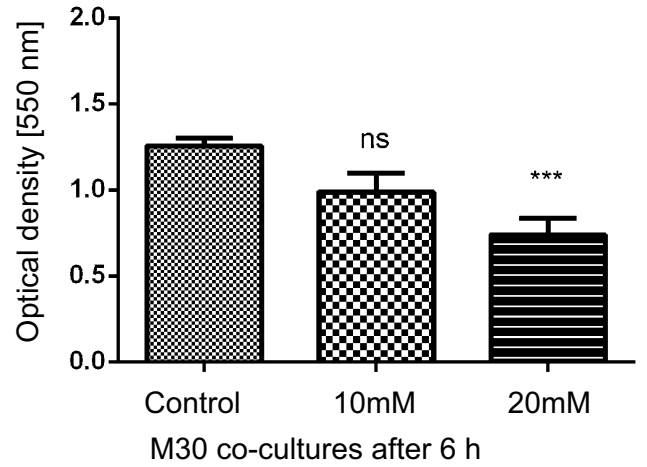

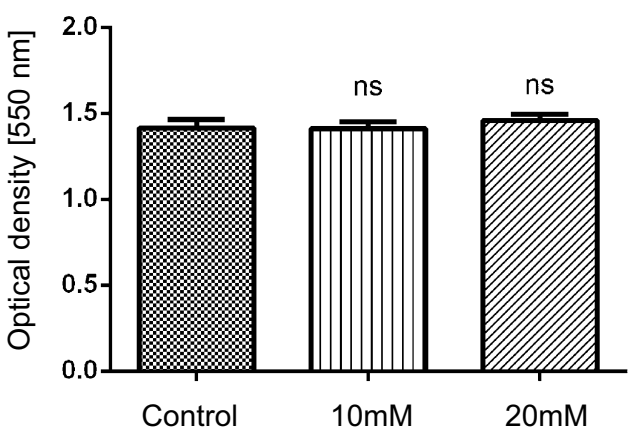

M5 co-cultures after $24 \mathrm{~h}$

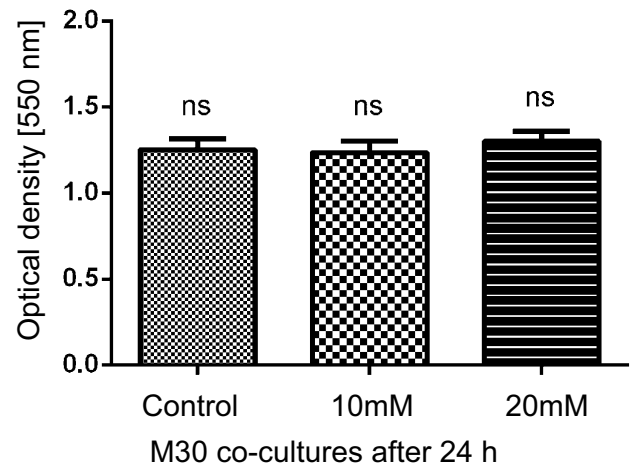

Fig. 2 Glial viability detected by MTT assay. a In M5 co-cultures, representing „physiological “ conditions, the glial viability was not altered by hyperammonemia. b The glial viability was significantly reduced after incubation with $20 \mathrm{mM} \mathrm{NH} 4 \mathrm{Cl}$ for $6 \mathrm{~h}$ in M30 co-cultures, representing "pathological" conditions ( $n=20$ independent experiments). This effect could not be detected following NH4Cl incubation for $24 \mathrm{~h}$. Data were collected by $n=8$ independent experiments. Comparisons between more than two groups with normal distribution were analyzed using One-way analysis of variance (One-way ANOVA) and Kruskal-Wallis test, ${ }^{*} p<0.05,{ }^{* *} p<0.01,{ }^{* * *} p<0.001$

western blots [see Additional file 1, a]. Longer incubation for $24 \mathrm{~h}$ with $\mathrm{NH} 4 \mathrm{Cl}$ did not alter the $\mathrm{Cx} 43$ expression in the astrocyte-microglia co-cultures.

\section{Influence of ammonia on AQP4 expression}

The AQP4 expression was significantly increased only in M5 astrocyte-microglia co-cultures treated with $10 \mathrm{mM}$ $\mathrm{NH} 4 \mathrm{Cl}$ for $6 \mathrm{~h}(\mathrm{p}<0.05)$ (Figs. 5a and $6 \mathrm{~b})$. An additional file shows original, unprocessed versions of full-length representative western blots [see Additional file 1, b]. This effect could not be determined after incubation with $\mathrm{NH} 4 \mathrm{Cl}$ for $24 \mathrm{~h}$. In M30 co-cultures, $\mathrm{AQP} 4$ expression was not changed after incubation with ammonia (Fig. 5b).

\section{Discussion}

In this study, we demonstrated a significant, dosedependent increase of microglial activation after incubation with ammonia both in physiological and pathological astrocyte-microglia co-culture model. Ammonia induced limited effects on $\mathrm{Cx} 43$ and AQP4 expression under physiological and pathological conditions.

\section{(See figure on next page.)}

Fig. 3 Immunocytochemical analyses of microglial phenotypes under hyperammonemia a A significant and dose-dependent increase of activated, rounded phagocytic type of microglia (RPT) was observed in M5 co-cultures by immunocytochemistry after incubation with $5 \mathrm{mM}$ and $10 \mathrm{mM}$ $\mathrm{NH} 4 \mathrm{Cl}$ for 6 and $24 \mathrm{~h}$ ( $\mathrm{n}=6$ independent experiments). In parallel, the amount of resting ramified type of microglia (RRT) decreased significantly and dose-dependent. $\mathbf{b}$ The amount of intermediate type of microglia (INT) was increased significantly in M5 co-cultures after incubation with $5 \mathrm{mM}$ and $10 \mathrm{mM} \mathrm{NH} 4 \mathrm{Cl}$ for $6 \mathrm{~h}$ and in M30 co-cultures after incubation with $3 \mathrm{mM}$ and $5 \mathrm{mM} \mathrm{NH4Cl}$ for $6 \mathrm{~h}$. c Similar results to a were obtained in M30 co-cultures. Data were collected by $n=3$ independent experiments. Comparisons between more than two groups with normal distribution were analyzed using One-way analysis of variance (One-way ANOVA) and Kruskal-Wallis test, ${ }^{*} p<0.05,{ }^{* *} p<0.01,{ }^{* * *} p<0.001$ 

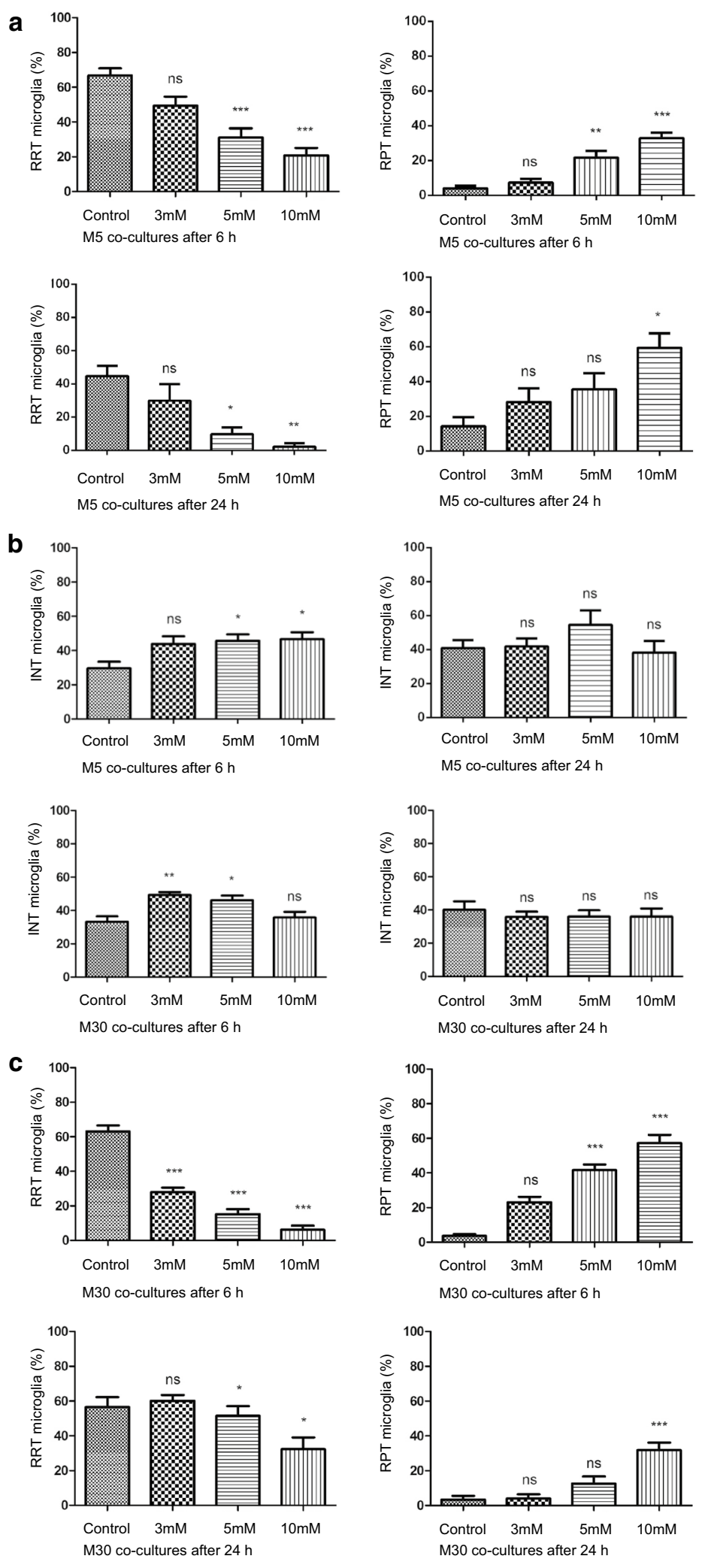

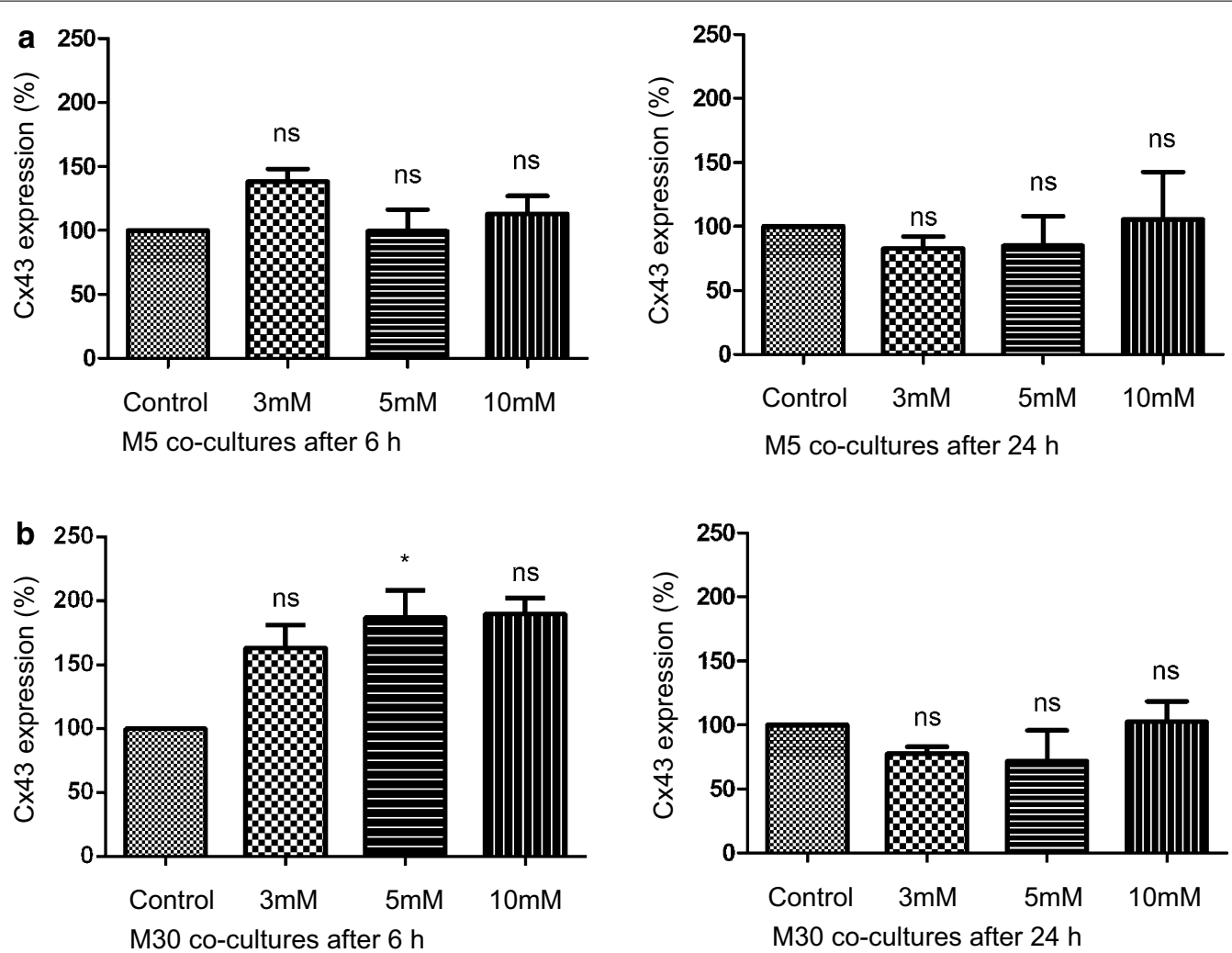

Fig. 4 Cx43 expression under hyperammonemia detected by western blot analysis. a The Cx43 expression in M5 co-cultures was not altered significantly after incubation with different concentrations of $\mathrm{NH} 4 \mathrm{Cl}$ for 6 or $24 \mathrm{~h}$ ( $\mathrm{n}=3$ independent experiments). b In M30 co-cultures, the Cx43 expression was significantly increased after $6 \mathrm{~h}$ incubation with $5 \mathrm{mM} \mathrm{NH} 4 \mathrm{Cl}$ and weakly, but not significantly increased after incubation with $10 \mathrm{mM} \mathrm{NH} 4 \mathrm{Cl}$. Incubation for $24 \mathrm{~h}$ with $\mathrm{NH} 4 \mathrm{Cl}$ did not change the $\mathrm{Cx} 43$ expression in the astrocyte-microglia co-cultures. Data were collected by $\mathrm{n}=4$ independent experiments. Comparisons between more than two groups with normal distribution were analyzed using One-way analysis of variance (One-way ANOVA) and Kruskal-Wallis test, ${ }^{*} p<0.05,{ }^{* *} p<0.01,{ }^{* * *} p<0.001$

\section{Glial cell viability under hyperammonemia}

Cytotoxic effects of ammonia on primary astrocyte cultures were previously demonstrated, but data about effects on astrocyte-microglia co-culture models were limited available [22, 23]. In our study, we examined the effects of ammonia on glial cell viability in astrocytemicroglia co-culture models under physiological and pathological conditions. A significant reduction of glial viability was observed after incubation with high-dose ammonia for $6 \mathrm{~h}$ in M30 astrocyte-microglia co-cultures, representing "pathological" conditions, but not after incubation for $24 \mathrm{~h}$. This could refer to a regulatory effect within the culture after a prolonged time of incubation and could further be explained by a very short half-life of ammonia (1-6.5 s). In M5 co-cultures, representing "physiological" conditions, the glial viability was not affected by hyperammonemia. This effect could not be modulated by changing the concentration of ammonia which underlines how stable and compensatory a physiological culture reacts to stress via ammonia even if the used concentrations was higher than described in previous studies of hepatic encephalopathy [22]. In another study, treatment with "low" concentrations of ammonia ( $5 \mathrm{mM}$ ) for $18 \mathrm{~h}$ had also no effects on the cell viability in astroglial-enriched cultures containing up to $10 \%$ microglia and in microglia-enriched cultures [24].

\section{Microglial activation and limited effects on Cx43 and AQP4 expression under hyperammonemia}

Our findings showing a significant and dose-dependent increase of activated microglia in M5 and M30 co-cultures after incubation with ammonia, are consistent with previous study results from primary microglia cultures $[17,18]$. Incubation of primary microglia cultures with ammonia caused an increase in synthesis and release of IL-6 and TNF $\alpha$ compared to untreated microglia [25]. However, in another study ammonium chloride did not influence LPS-induced up-regulation of transcription of microglia activation markers such as IL-6 and TNF $\alpha$ in microglia mono-cultures, but reduced it in co-cultured 

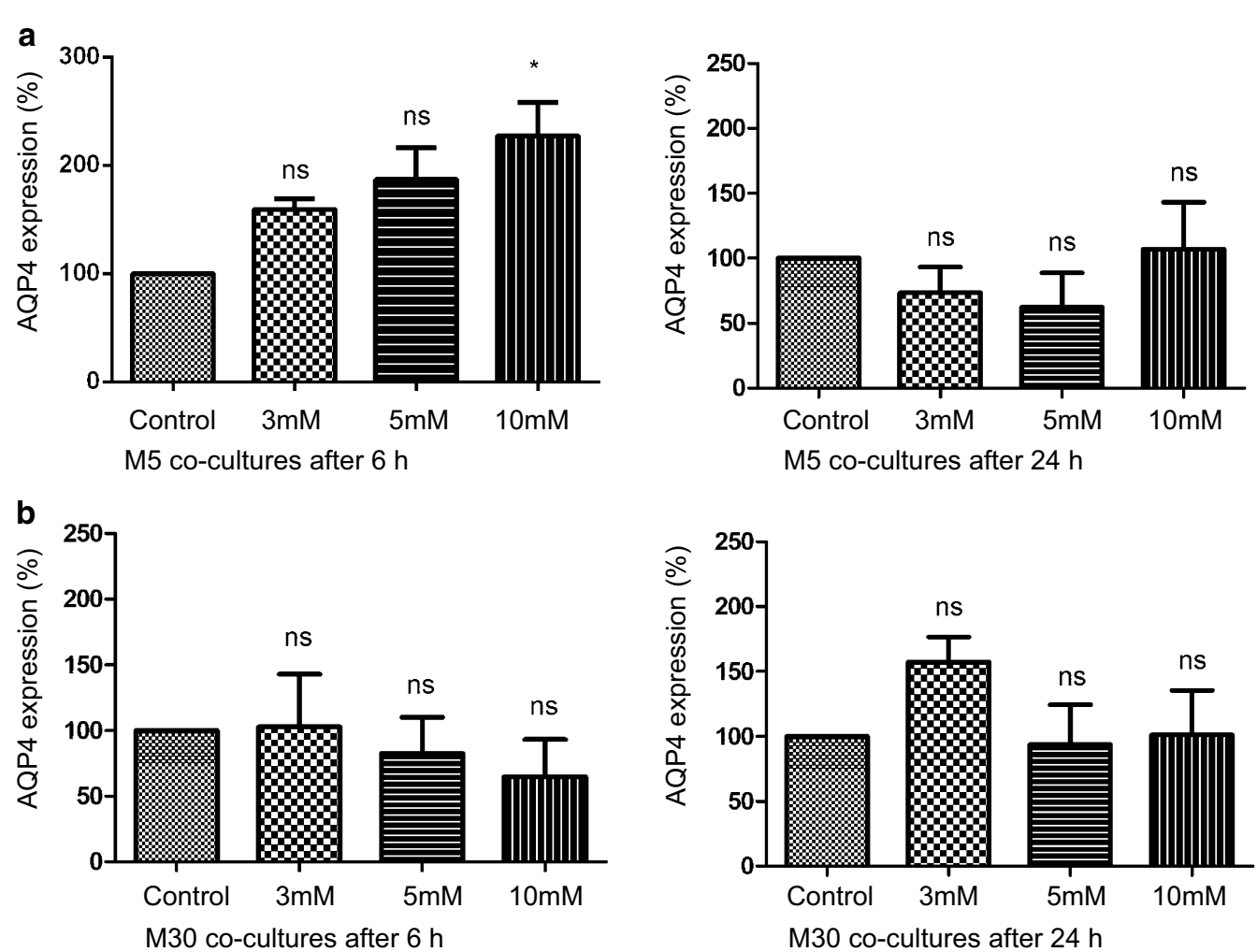

Fig. 5 Western blot analysis of AQP4 expression under hyperammonemia. a The AQP4 expression was increased significantly only in M5 astrocyte-microglia co-cultures treated with $10 \mathrm{mM} \mathrm{NH} 4 \mathrm{Cl}$ for $6 \mathrm{~h}$. This effect was not shown after incubation with NH4Cl for $24 \mathrm{~h}(\mathrm{n}=4$ independent experiments). $\mathbf{b}$ In M30 co-cultures, AQP4 expression was not altered by ammonia. Data were collected by $n=4$ independent experiments. Comparisons between more than two groups with normal distribution were analyzed using One-way analysis of variance (One-way ANOVA) and Kruskal-Wallis test, ${ }^{*} p<0.05,{ }^{* *} p<0.01,{ }^{* *} p<0.001$

astrocytes and microglia [25]. These results indicated that astrocytes reduced the up-regulation of microglia activation markers induced by LPS [25]. Further studies are required to evaluate the exact effects of ammonia on microglia activation in the different contexts of HE.

On the other hand, there is evidence for interactions between astrocytes and microglia under hyperammonemia conditions contributing to astrocyte swelling [18]. Previous in vitro studies by Faustmann et al. [15] demonstrated that microglia activation in M30 astrocytemicroglia co-culture model, representing "pathological" conditions, was associated with reduced astroglial Cx43 expression. However, microglial activation under hyperammonemia was related to slightly increase in Cx43 expression only in one condition in our study. The biological relevance of these minimal and rare significances needs to be questioned. The intercellular coupling in the astroglial network may be modulated by the activation of microglia under pathological conditions in different ways.

The AQP4 expression in our study was sligtly increased after incubation with ammonia only in one condition similar to Cx43. This is consistent with results of previous studies [26]. Further, AQP4 up-regulation after incubation with ammonia correlated with astrocyte swelling [26]. The exact mechanisms leading to increase in AQP4 expression are not yet known. Protein tyrosine nitration was detected in ammonia-treated astrocyte cultures, thus ammonia-induced nitrosative stress may contribute to the up-regulation of AQP4 [27]. It is also conceivable that microglial activation following exposure to pathophysiological concentrations of ammonia can modulate AQP4 expression. However, in our study the ammonia induced microglial activation was associated with a minimal and rare significance in expression of AQP4.

Limitation of our study was that only one method was used for the detection of $\mathrm{Cx} 43$ and AQP4 expression under hyperammonemia in the co-culture model, e.g. additional quantitative real-time mRNA expression analysis could be useful and can be focus of future projects. Functional coupling studies of astrocytes and the recording of the astrocytes membrane potential are planned for further investigations [15]. 


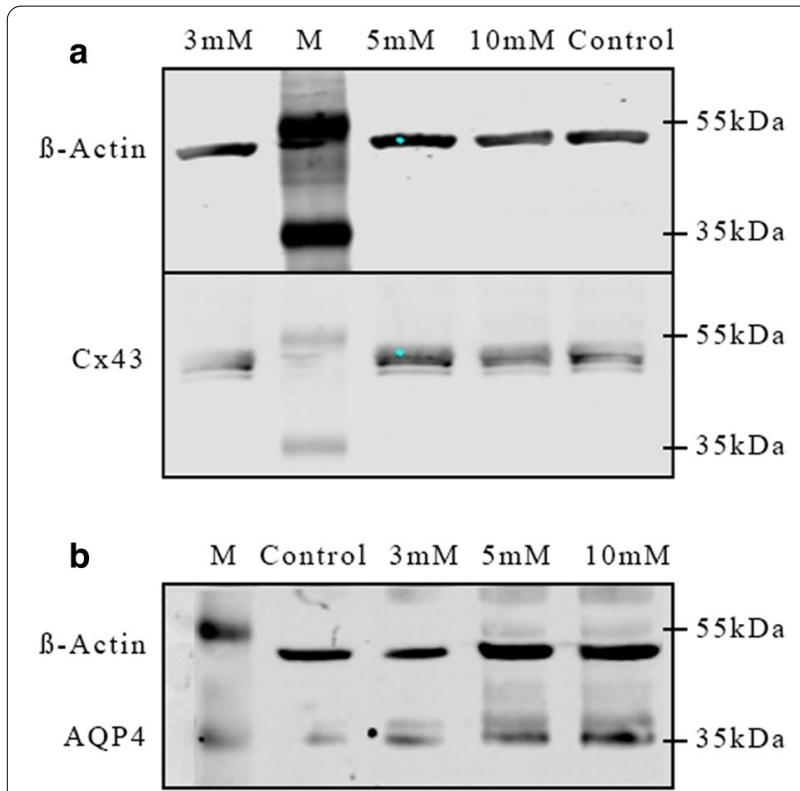

Fig. 6 Representative western blots showing the slightly increased Cx43 protein expression (a) in M30 co-cultures after $6 \mathrm{~h}$ incubation with $5 \mathrm{mM} \mathrm{NH} 4 \mathrm{Cl}$ and increased AQP4 expression (b) in M5 co-cultures after $6 \mathrm{~h}$ incubation with $10 \mathrm{mM} \mathrm{NH} 4 \mathrm{Cl}$

\section{Conclusions}

The novel aspect of our study was the significant microglial activation and decrease of viability after $\mathrm{NH} 4 \mathrm{Cl}$ incubation in different set-ups of in vitro astrocyte-microglia co-culture model, contributing to better understanding of pathophysiological mechanisms of HE. Hyperammonemia led to limited effects on $\mathrm{Cx} 43$ and AQP4 expression, the relevance of these minimal changes should be viewed with caution. But the astrocyte-microglia co-culture model offers the possibility of investigating the endogenous inflammatory reaction and the cytokine expression under ammonia in a differentiated manner.

\begin{abstract}
Abbreviations
AQP4: Aquaporin 4; CNS: Central nervous system; Cx43: Connexin 43; DMEM: Dulbecco's minimal essential medium; DAPI: 4',6-Diamidino-2-phenylindole; GJs: Gap junctions; HE: Hepatic encephalopathy; Iba1: Ionized calciumbinding adaptor molecule 1; IL-6: Interleukin 6; INT: Intermediate type; LPS: Lipopolysaccharide; MTT: 3-(4,5-Dimethylthiazol-2-yl)-2,5-diphenyltetrazolium bromide; NH4Cl: Ammonium chloride; PBS: Phosphatebuffered saline; PVDF: Polyvinylidene fluoride; RRT: Resting ramified type; RPT: Rounded phagocytic type; SDS: Sodium dodecyl sulfate; TNFa: Tumor necrosis factor a.
\end{abstract}

\section{Supplementary Information}

The online version contains supplementary material available at https://doi. org/10.1186/s12868-021-00628-1.

Additional file 1. Original, unprocessed versions of full-length representative western blots with regard to Fig. 6, showing (a) slightly increased Cx43 protein expression in M30 co-cultures after $6 \mathrm{~h}$ incubation with 5 $\mathrm{mM} \mathrm{NH} 4 \mathrm{Cl}$ and increased AQP4 expression (b) in M5 co-cultures after $6 \mathrm{~h}$ incubation with $10 \mathrm{mM} \mathrm{NH} 4 \mathrm{Cl}$.

\section{Acknowledgements}

Not applicable.

\section{Authors' contributions}

PMF conceived and designed the experiments. AT and ZM performed the experiments. All authors (FSI, TJF, FC, AT, ZM, PMF) analyzed and interpreted the experimental data. FSI and TJF wrote the manuscript. All authors have agreed to be personally accountable for own contributions and to ensure that questions related to the accuracy or integrity of any part of the work, even ones in which the author was not personally involved, are appropriately investigated, resolved, and the resolution documented in the literature. All authors read and approved the final manuscript.

\section{Funding}

Open Access funding enabled and organized by Projekt DEAL. No targeted funding reported.

\section{Availability of data and materials}

The datasets used or analyzed during this study are available from the corresponding author on reasonable request.

\section{Declarations}

\section{Ethics approval and consent to participate}

All experiments were performed according to the German animal welfare act and the ethical standards of the Ruhr University Bochum, and were approved by the local authorities in Bochum, Germany.

\section{Consent for publication}

Not applicable.

\section{Competing interests \\ FSI, TJF, FC, AT, ZM, PMF declare that they have no competing interests.}

\section{Author details}

${ }^{1}$ Department of Neurology, University Hospital Knappschaftskrankenhaus Bochum, Ruhr University Bochum, Bochum, Germany. ${ }^{2}$ Department of Psychiatry and Psychotherapy, Medical Faculty, Heinrich Heine University, Düsseldorf, Germany. ${ }^{3}$ Department of Neuroanatomy and Molecular Brain Research, Ruhr University Bochum, Bochum, Germany. ${ }^{4}$ International Graduate School of Neuroscience, Ruhr University Bochum, Bochum, Germany.

Received: 13 August 2020 Accepted: 16 March 2021

Published online: 25 March 2021

\section{References}

1. Brumback RA, Lapham LW. DNA synthesis in Alzheimer type II astrocytosis. The question of astrocytic proliferation and mitosis in experimentally induced hepatic encephalopathy. Arch Neurol. 1989;46:845-8.

2. Suárez I, Bodega G, Fernández B. Glutamine synthetase in brain: effect of ammonia. Neurochem Int. 2002;41:123-42.

3. Bobermin LD, Wartchow KM, Flores MP, Leite MC, Quincozes-Santos A, Gonçalves CA. Ammonia-induced oxidative damage in neurons is prevented by resveratrol and lipoic acid with participation of heme oxygenase 1. Neurotoxicology. 2015;49:28-35.

4. Martinez-Hernandez A, Bell KP, Norenberg MD. Glutamine synthetase: glial localization in brain. Science. 1977;195:1356-8.

5. Norenberg MD, Baker L, Norenberg LO, Blicharska J, Bruce-Gregorios $\mathrm{JH}$, Neary JT. Ammonia-induced astrocyte swelling in primary culture. Neurochem Res. 1991;16:833-6.

6. Norenberg MD, Jayakumar AR, Rama Rao KV, Panickar KS. New concepts in the mechanism of ammonia-induced astrocyte swelling. Metab Brain Dis. 2007;22:219-34.

7. Rama Rao KV, Jayakumar AR, Tong X, Alvarez VM, Norenberg MD. Marked potentiation of cell swelling by cytokines in ammonia-sensitized cultured astrocytes. J Neuroinflammation. 2010;7:66.

8. Tofteng F, Hauerberg J, Hansen BA, Pedersen CB, Jørgensen L, Larsen FS. Persistent arterial hyperammonemia increases the concentration of 
glutamine and alanine in the brain and correlates with intracranial pressure in patients with fulminant hepatic failure. J Cereb Blood Flow Metab. 2006;26:21-7.

9. Thumburu KK, Dhiman RK, Vasishta RK, Chakraborti A, Butterworth RF, Beauchesne $\mathrm{E}$, et al. Expression of astrocytic genes coding for proteins implicated in neural excitation and brain edema is altered after acute liver failure. J Neurochem. 2014;128:617-27.

10. Nielsen S, Nagelhus EA, Amiry-Moghaddam M, Bourque C, Agre $P$, Ottersen OP. Specialized membrane domains for water transport in glial cells: highresolution immunogold cytochemistry of aquaporin-4 in rat brain. J Neurosci. 1997;17:171-80.

11. Amiry-Moghaddam M, Xue R, Haug FM, Neely JD, Bhardwaj A, Agre $P$, et al. Alpha-syntrophin deletion removes the perivascular but not endothelial pool of aquaporin-4 at the blood-brain barrier and delays the development of brain edema in an experimental model of acute hyponatremia. FASEB J. 2004;18:542-4.

12. Yang JH, Song ZJ, Liao CD, You LY, Xu Y, Yang J, et al. The relationship of the expression of aquaporin- 4 and brain edema in rats with acute liver failure. Zhonghua Gan Zang Bing Za Zhi. 2006;14:215-6.

13. Wang LQ, Zhu SM, Zhou HJ, Pan CF. Expression of aquaporin-4 during brain edema in rats with thioacetamide-induced acute encephalopathy. Zhonghua Yi Xue Za Zhi. 2011;91:2573-7.

14. Eefsen M, Jelnes P, Schmidt LE, Vainer B, Bisgaard HC, Larsen FS. Brain expression of the water channels aquaporin- 1 and -4 in mice with acute liver injury, hyperammonemia and brain edema. Metab Brain Dis. 2010;25:315-23.

15. Faustmann PM, Haase CG, Romberg S, et al. Microglia activation influences dye coupling and Cx43 expression of the astrocytic network. Glia. 2003:42:101-8

16. Gehrmann J, Matsumoto Y, Kreutzberg GW. Microglia: intrinsic immuneffector cell of the brain. Brain Res Brain Res Rev. 1995:20:269-87.

17. Zemtsova I, Görg B, Keitel V, Bidmon HJ, Schrör K, Häussinger D. Microglia activation in hepatic encephalopathy in rats and humans. Hepatology. 2011;54:204-15.

18. Rao KV, Brahmbhatt M, Norenberg MD. Microglia contribute to ammoniainduced astrocyte swelling in culture. Metab Brain Dis. 2013;28:139-43.
19. Dermietzel R, Hertberg EL, Kessler JA, Spray DC. Gap junctions between cultured astrocytes: immunocytochemical, molecular, and electrophysiological analysis. J Neurosci. 1991;11:1421-32.

20. Bobermin LD, Arús BA, Leite MC, Souza DO, Gonçalves CA, QuincozesSantos A. Gap junction intercellular communication mediates ammoniainduced neurotoxicity. Neurotox Res. 2016;29:314-24.

21. Bradford MM. A rapid and sensitive method for the quantitation of microgram quantities of protein utilizing the principle of protein-dye binding. Anal Biochem. 1976:72:248-54.

22. Bosoi CR, Rose CF. Identifying the direct effects of ammonia on the brain. Metab Brain Dis. 2009;24:95-102.

23. Shawcross $D$, Jalan R. The pathophysiologic basis of hepatic encephalopathy: central role for ammonia and inflammation. Cell Mol Life Sci. 2005;62:2295-304

24. Andersson AK, Rönnbäck L, Hansson E. Lactate induces tumour necrosis factor-alpha, interleukin-6 and interleukin-1 beta release in microglial- and astroglial-enriched primary cultures. J Neurochem. 2005;93:1327-33.

25. Karababa A, Groos-Sahr K, Albrecht U, Keitel V, Shafigullina A, Görg B, et al. Ammonia attenuates LPS-induced upregulation of pro-inflammatory cytokine mRNA in co-cultured astrocytes and microglia. Neurochem Res. 2017;42:737-49.

26. Rama Rao KV, Chen M, Simard JM, Norenberg M. Increased aquaporin-4 expression in ammonia-treated cultured astrocytes. Neuro Report. 2003:14:2379-82.

27. Schliess F, Görg B, Fischer R, et al. Ammonia induces MK-801-sensitive nitration and phosphorylation of protein tyrosine residues in rat astrocytes. FASEB J. 2002;16:739-41.

\section{Publisher's Note}

Springer Nature remains neutral with regard to jurisdictional claims in published maps and institutional affiliations.
Ready to submit your research? Choose BMC and benefit from:

- fast, convenient online submission

- thorough peer review by experienced researchers in your field

- rapid publication on acceptance

- support for research data, including large and complex data types

- gold Open Access which fosters wider collaboration and increased citations

- maximum visibility for your research: over $100 \mathrm{M}$ website views per year

At BMC, research is always in progress.

Learn more biomedcentral.com/submissions 